\title{
1916-2016 The first hundred years of the Ophthalmology Department
}

\author{
Paulo Gelman Vaidergorn
}

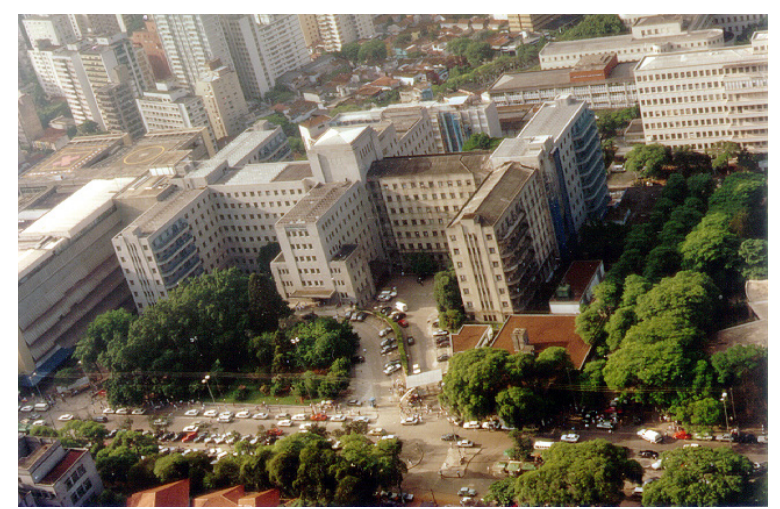

\section{HISTORICAL PERSPECTIVE}

\section{Early beginnings, with Professor João Paulo da Cruz} Britto (1916-1947)

$\left\{\begin{array}{l}\text { y 1916, as the European continent is engulfed in } \\ \text { "the war to end all wars", here, in the faraway }\end{array}\right.$ southern hemisphere, on Brazilian lands, Arnaldo Vieira de Carvalho keeps pursuing his dream of consolidating a new Medicine School. To fulfill it he has, over the preceding years, made contact with renowned specialists, teachers of different medical fields, so as to bring and congregate them upon his noble ideal. This way, a young doctor, recently arrived from Europe caught his attention. João Paulo da Cruz Britto, who had graduated at the Rio de Janeiro

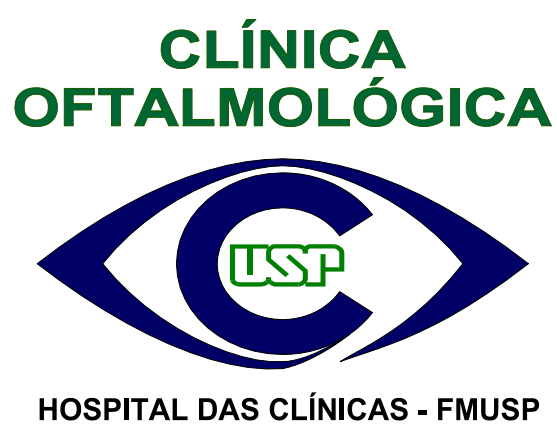

Medical school, had made specialization studies with the great European masters of the times at Vienna, Berlin and London. J. Britto, as he became known, accepts Arnaldo's invitation to head the newly founded Ophthalmological department. The Clinic, those distant days, was located at the Santa Casa de Misericórdia, downtown São Paulo, and the opening class, on February $14^{\text {th }}, 1916$, was about "Ophthalmology and its relations with general medicine". Over the following months the young professor focused on providing the Department with more ample and satisfactory premises, compatible with the teaching of the specialty. For that he counted with the help of Medical Faculty director Diogo de Faria and Sinésio Rangel Pestana, then Santa Casa's superintendent.

Professor of the Departament of the Ophtalmology at HCFMUSP.

Mailing address: Av. Dr. Enéas de Carvalho Aguiar, 255 - $6^{\circ}$ andar, Sala 6120. CEP: 05403-00 - São Paulo, SP, Brasil. E-mail: pgelmann@yahoo.com 


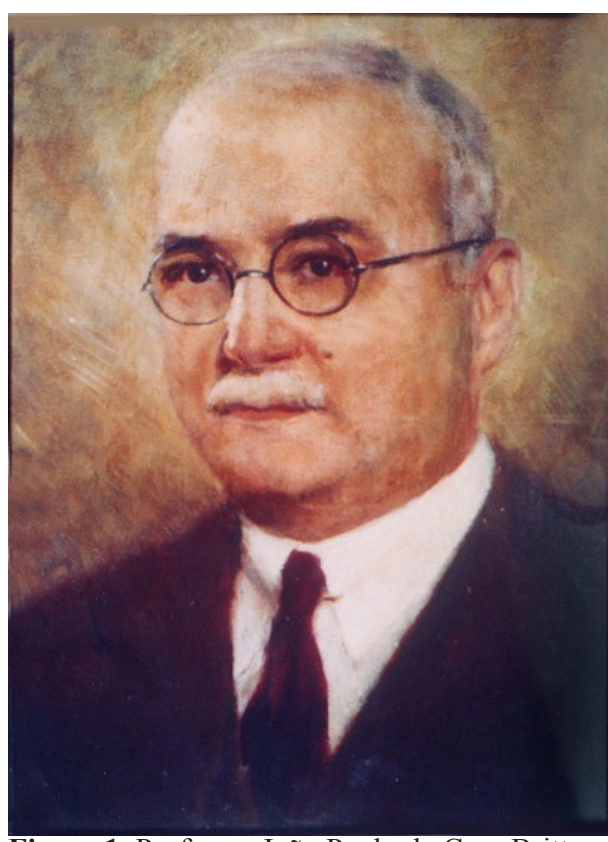

Figure 1. Professor João Paulo da Cruz Britto

J. Britto emphasised pedagogy, so he ordered a large amphitheater be built, where classes could be given not just to the House's students, but attendance was also made free to the town's doctors in general. He thus sought to democratize access to knowledge, aware of the huge educational task the country needed. He was assisted, those days, by Dr. Cyro de Rezende (who would later succeed him), as well as Drs. Pereira Gomes, Benedicto de Paula Santos and Durval Prado.

The semiological and clinical aspects of the specialty were greatly stressed by J. Britto, whose classes stood out for clarity, didacticism and plenty of teachings. He would usually illustrate them with drawings and slides, so as to make them as pleasant as possible. For that reason he attracted to his lectures not only medical school students but also scores of outside ophthalmologists and even doctors from other specialties eager to prime their knowledge.

In 1947, as the General Hospital building was finished, the Ophthalmology Department left the Santa Casa premises and moved on. Barely, though, had the professor time to get used to the new quarters, as a fulminating aortal aneurism took him from the living.

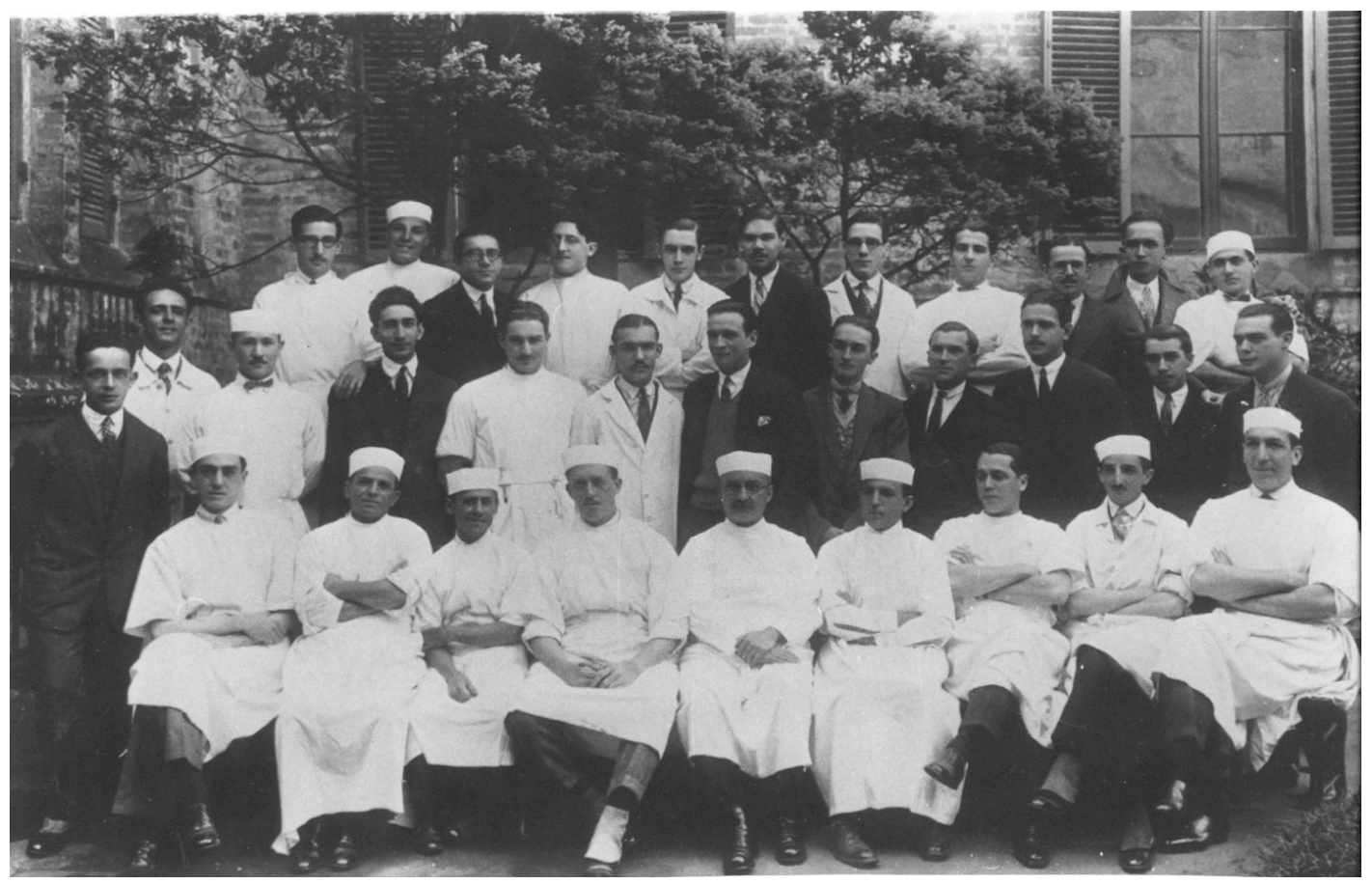

Figure 2. Picture taken at the gardens of Santa Casa, mid ' $20^{\text {ies }}$. Sitting, far left Dr. Cyro de Rezende, center Prof. J. Britto and far right Dr. Jacques Tupinambá. Standing behind students 


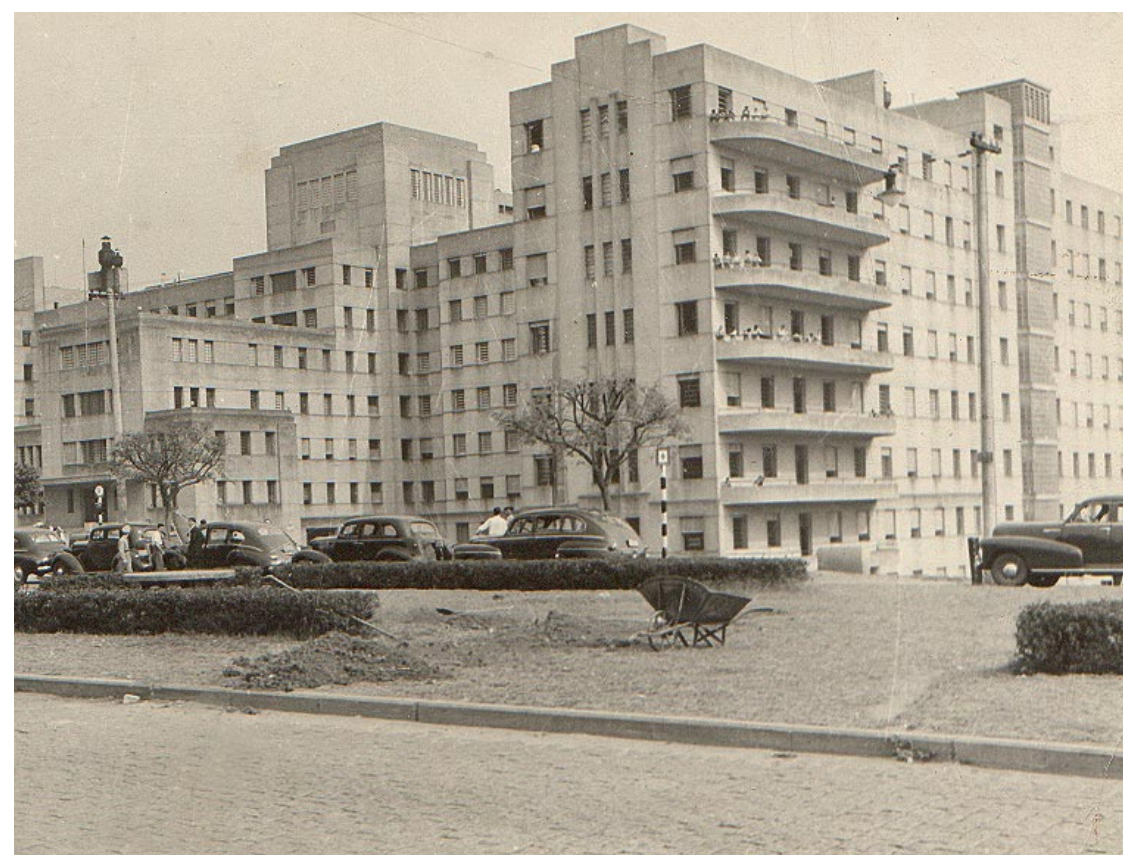

Figure 3. 1948: General Hospital, Central Institute, soon after completion

\section{Professor Cyro de Rezende (1947-1962)}

One of Brazil's greatest Ophthalmologists, he was born in 1905. As both his parents were conscious about the importance of a good education, the young man was put to attend the best schools and at 17 started his medical apprenticeship at Rio de Janeiro. After graduating in 1927, took the way to Europe, studying Ophthalmology for two years at the Universities of Berlin and Vienna.

Back in Brazil, became assistant to professor Britto at Santa Casa de Misericórdia de São Paulo.

\section{His Carreer}

From early on the young ophthalmologist showed keen interest for teaching and scientific activities, intensely participating in the Ophthalmological Congresses. Numerous scientific works, classes, lectures and courses followed, and up he moved the ranks of academy, so in 1938 J. Britto made him First Assistant. His leitmotiv has always been to better prepare those initiating in the field, so he concerned himself, since the beginning, with organizing courses for newly graduated doctors who were starting their training in Ophthalmology (those days there was no organized Residency yet). He engineered a program that sought to comprise the diverse knowledge areas of the subspecialties, helped on the classes by Drs. Jacques Tupinambá, Armando Gallo, Plínio de Toledo Piza, Paulo Braga de Magalhães and Carlos Gama. Surgical training was ministered by Drs. Britto, Jorge Wilmersdorf and João Carlos Celeste. There was also the outpatient clinic, basically patient examination. He thus pioneered the organized medical training in Ophthalmology in Brazil. Nine years after being nominated first assistant, with the demise of J. Britto, he took over as Head of the Department, which would be his tenure for 15 years. All over the years of his term he was known to motivate young doctors to improve themselves, using his personal influence to arrange for several to do fellowships abroad. That way, many of those who came to learn Ophthalmology moved on academically and also became professors, as Dr. Rezende strived to make those around him move forward alongside him. What really distinguished him, his trade mark, was the push he gave others to advance on their careers. 


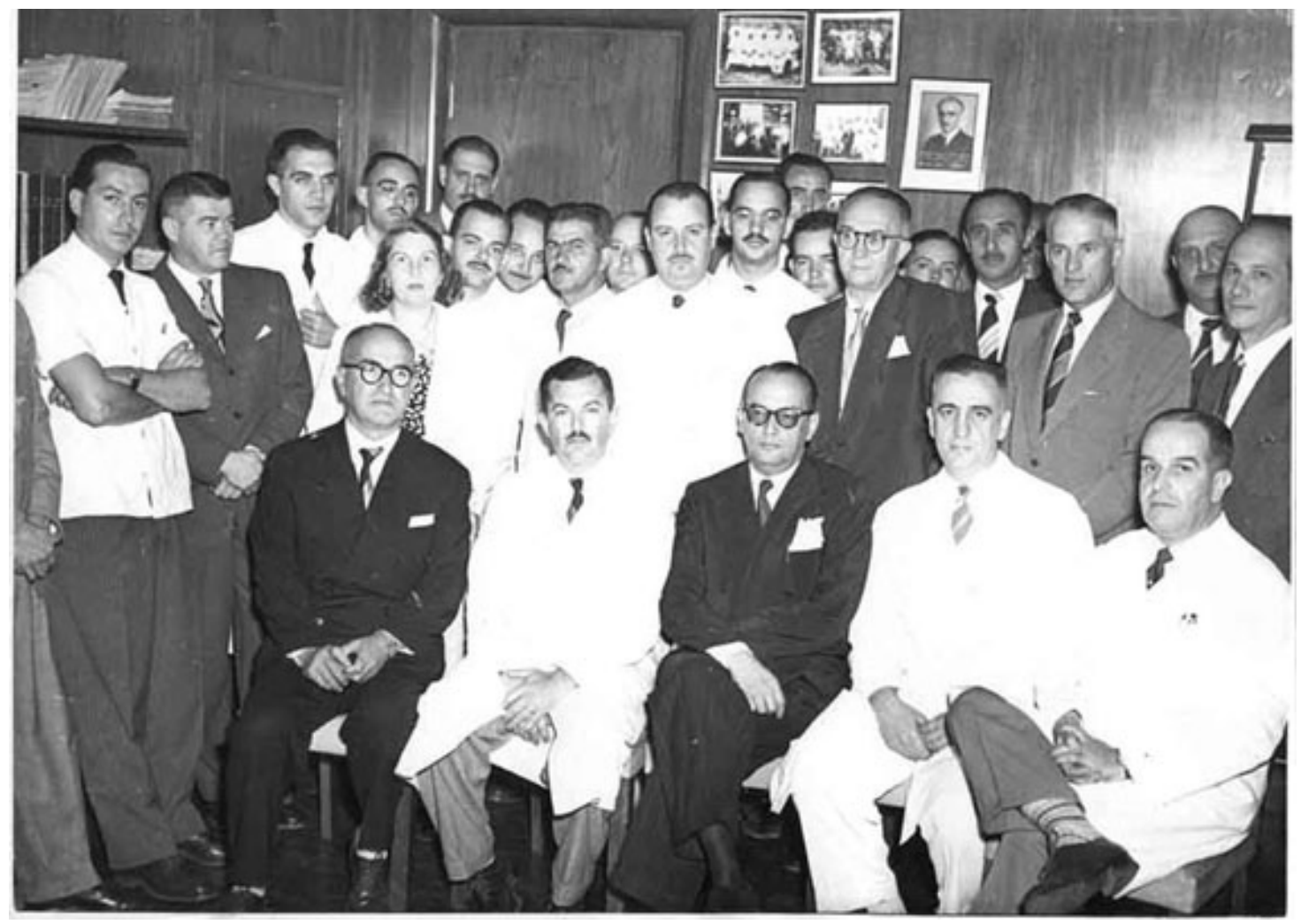

Figure 3. (Picture taken at the library, 1956): Sitting, left to right: Dr. Francisco Amendola, Dr.Plinio de Toledo Piza, Dr. Sylvio de Abreu Fialho, Prof. Cyro de RFezende, Dr. José de Mesquita Sampaio. Standing, left to right: Dr. Tanganelli, Dr. Guilherme Pereira, Dr. João Celeste, Dr. Vasco Moreira Lisboa, Dr. Dante Nesse, Dra. Drina Coelho Ungaretti, Dr. Coriolano Eliezer, Dr. João Batista Alves, Dr. Jorge C. Wilmersdorf, Dr. Edson Teixeira, Dr. Silvio de Toledo, Dr. Wilson Guimarães, ?, ?, Dr. Artur Souza Martins, ?, ?, Dr. Moacir Cunha, ?, Dr. Aldo Bartolomeu

\section{The individual}

(And a particular trait of his character)

In a time when healthy lifestyle concerns were virtually nonexistent, Dr. Rezende would repeatedly call attention to its importance. Never smoked, in an era when smoking was considered glamorous and most doctors did it. Didn't drink, when drinking was virtually de rigueur and extolled people to exercise regularly, especially walking, thought by him to be the most advisable of sports. He himself, often after a day's work, would walk from his downtown office all the way home, a stretch of several kilometers. In so, he was taken for eccentric, as "why wouldn't he go by car, like everybody else?". But he had a clear mind about the importance of regular physical practice and even gave a lecture for lay people about "Sports and the eye". That, in 1935!

Certainly a man ahead of his time.

\section{Succession}

One Sunday afternoon in 1962, when driving on a road back to São Paulo, a head-on crash with a truck took the Professor's life, and the Department was taken over by Dr. Paulo Braga de Magalhães, Dr. Rezende's assistant since the days of Santa Casa.

\section{Prof. Paulo Braga de Magalhães (1962-1983)}

A man of peaceful temper who wouldn't impose his will over subordinates, Dr. Braga tried to continue on his predecessor activities, not an easy task. Those were trying times: the cold war, social unrest, a military coup-d'etat...

Science, albeit, moved fast, and so did Ophthalmology.

During his term college education greatly expanded, medicine included, with ever-increasing numbers of newly- 
graduated doctors, many of whom took interest in our field. Aware of that, Dr. Braga increased residency places from two to five and, near the end of his tenure, a new, large outpatient building was finished.

Over his years he was helped by Drs. Suel Abujamra, Newton Kara-José, Hisashi Suzuki, Carlos Alberto Rodrigues Alves, Alberto Betinjane and Remo Susanna Jr.

Dr. Braga was the first Professor to do compulsory retirement at 70, but kept on participating in the Department by giving classes and helping on the teaching activities. He was succeeded in 1983 by Dr. Jorge Caldeira.

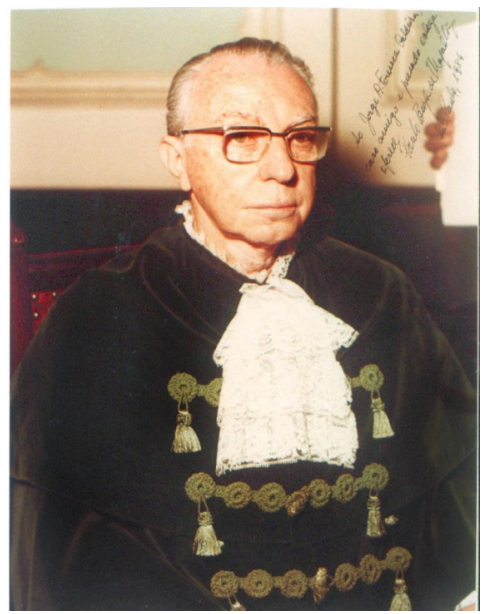

Figure 4. Prof. Paulo Braga de Magalhães

\section{Prof. Jorge Alberto Fonseca Caldeira (1983-1997)}

His keynote was to invest in teaching, mainly postgraduation. Relevant to notice that those days scientific production and new discoveries were proceeding at a fast rate, making continuing medical education a must. Dr. Caldeira was also mindful about extending the benefits of attendance to the Ophthalmological Department facilities, and, viewing those eager to better their knowledge, started a fellowship program. The Department, thus, greatly expanded, not only in number of doctors and patient volume but also in terms of scientific and didactical production. He was assisted by Drs Milton Ruiz Alves, Roberto Malta, Samir Jacob Bechara and Mário Luiz Monteiro.

After compulsory retirement he followed the example of his predecessor and, too, continued to teach and participate in our annual congresses, committing his knowledge and experience to the good of the Department.

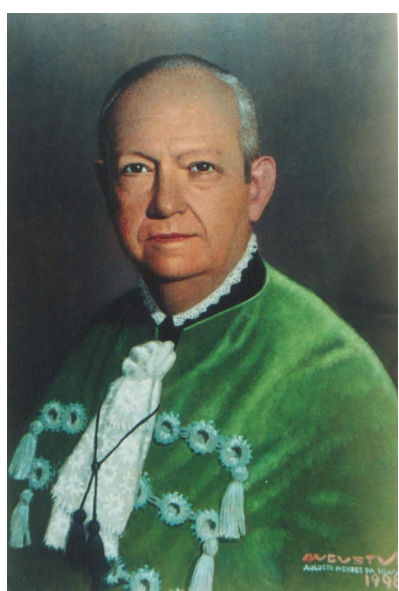

Figure 5. Professor Jorge Alberto Fonseca Caldeira

\section{XXI ${ }^{\text {st }}$ century, with Prof. Newton Kara José (1997-2008)}

In 1997 the Department's command passed on to Prof. Newton Kara José. The new century brought along challenges that demanded a firmer stance on the University's social engagement, so the Department should strengthen its three mainstays, namely education, research and community service. Accordingly, since the beginning, Dr Newton sought to increase the social commitment, expanding residency places from five to fourteen. He also created the outpatient Cataract Surgery Center, that made possible to multiply the number of surgeries, which passed from 50 to 430 monthly. Over the entire General Hospital body of Clinics our Department became first in income and the post-graduation area, under the command of Dr. Carlos Alberto Rodrigues Alves took a national character, with students coming from all over the country, their number growing from eight to 44 .

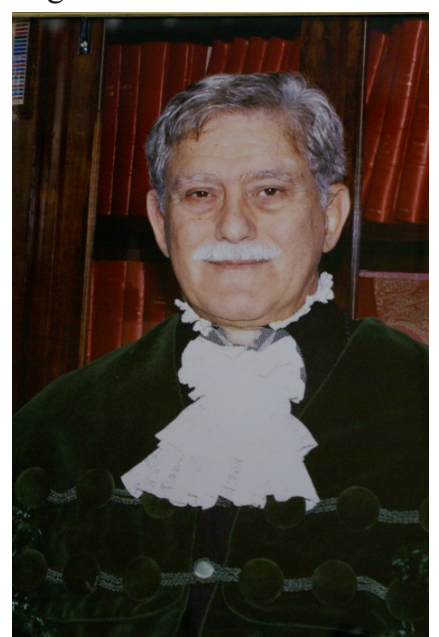

Figure 6. Professor Newton Kara José 
He also created the Cataract Program, directed to the lower classes, aiming at detecting and quickly operating large numbers of those affected. Another initiative was targeted at first grade children, searching to identify the visually impaired and prescribing them glasses. Quoting him: "As it is known, the simple wear of spectacles and the resulting better vision might mean the difference between social exclusion and a productive life". And also: "The medical professional must respond to the Society needs and fulfill what it expects from it. Just to know is no longer enough; one must act".

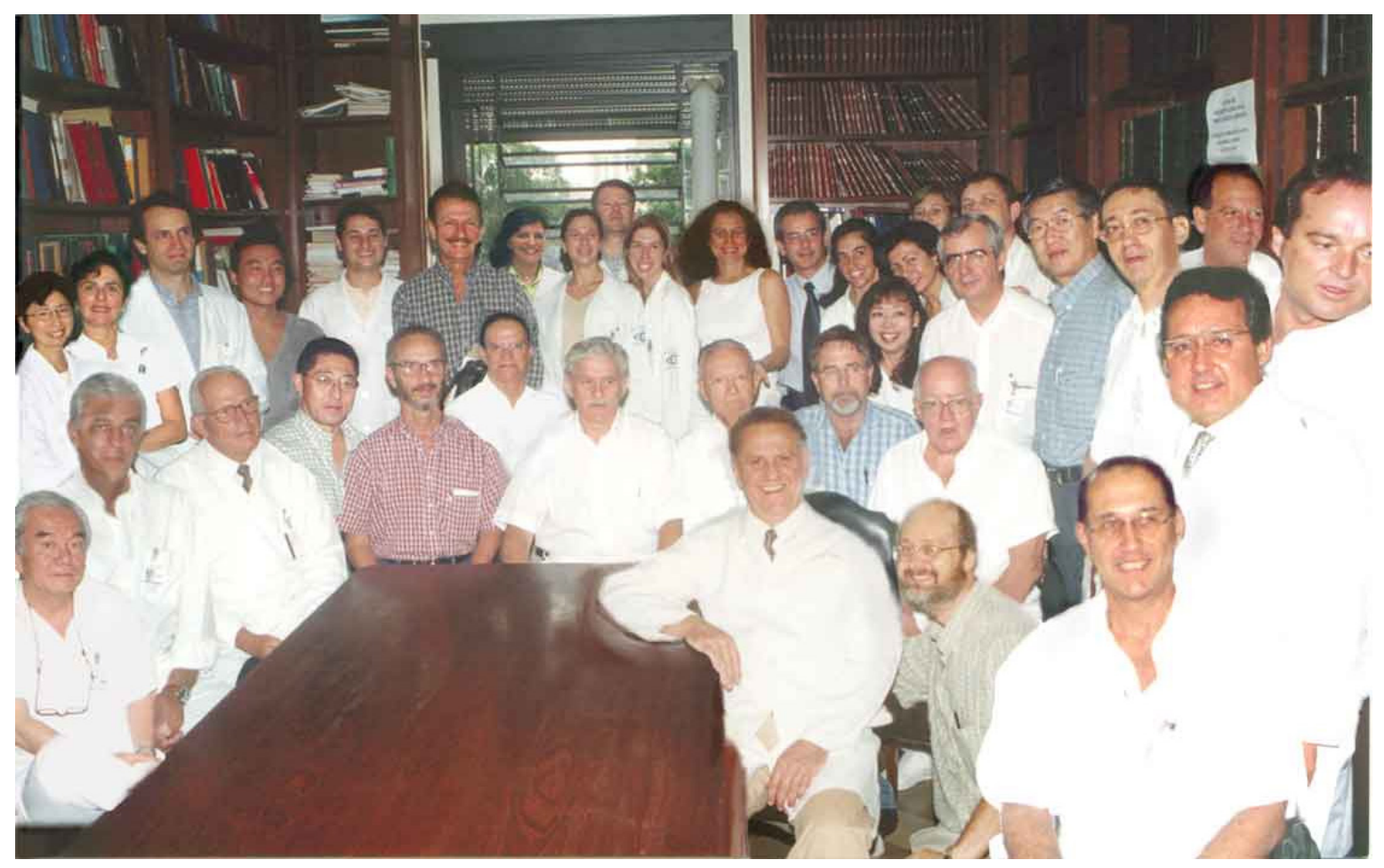

Figure 7. Ophthalmology Department faculty, 2001

\section{Professor Remo Susanna Jr. (2009 - ～）}

As Professor Newton Kara Jose retired in 2008 the post of Department Head was occupied by Dr. Remo Susanna Jr, who had already presided over a number of scientific societies, both national and international. His large experience in the area enabled him to a comprehensive view of problems and their possible remedies. Knowing that, although the Department was first in revenue, its needs were also huge, he took action, since the beginning, attempted to maximize resorts by better management and business efficacy.

In striving to boost the Department's scientific production he instituted a number of stimuli and prizes, as to motivate engagement among doctors, with the resulting increase in peer-reviewed publications. A Teaching Commission was established, which entirely restructured both medical school graduation and the internship, offering a better, much-praised program, and a novel residency curriculum was implemented. Also their work, the new post-graduation program has been exported to Portugal and institutionalized to other medical schools all over Brazil.

As after several decades of constant use our library and theater were decaying and in urgent need of renovation, Prof. Remo sought support from some affluent donors, whose backing made possible a complete overhaul of both, with resulting first-rate facilities. Thanks, also, to their expressive funding, a score of state-of-the-art equipment has been acquired, yielding more accurate diagnosis and better-performed surgeries.

He also maintained the social program of providing ophthalmic check-ups to detect vision deficiencies among first grade students, and started the "Bandeira Paulista", aimed at sending ophthalmologists to assist needy populations in poor, faraway regions of the country. 


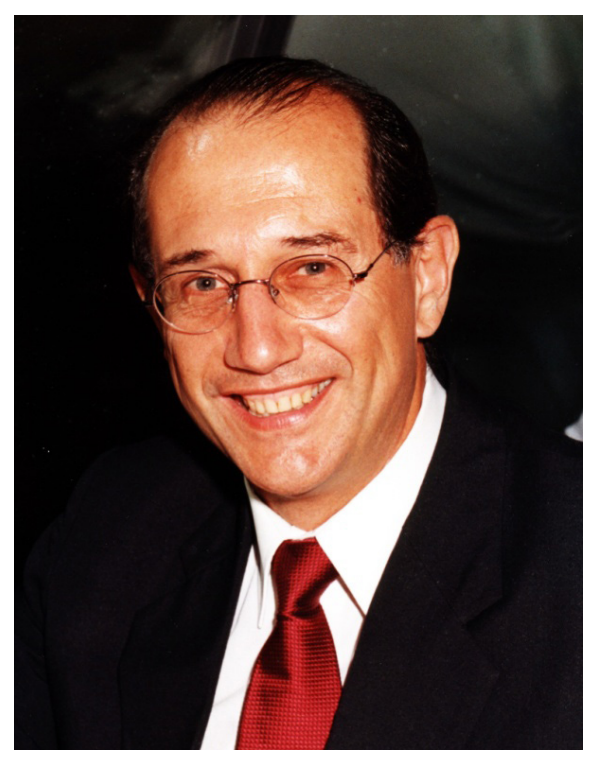

Figure 8. Professor Remo Susanna Jr

Second only to the National Brazilian, our annual congress, with over 3500 participants, offers an opportunity to ophthalmologists from around the country to update their knowledge in all the distinct fields of the specialty.

\section{Future trends}

A key program presently being developed aims at promoting resident training in world-renowned institutions abroad. In so, a number of agreements with foreign Universities have been signed, leading to the benefit of promising young doctors who are being privileged to a scientific stint overseas.

Aiming at developing new leaderships, the most promising residents are offered mentor support and regarding the specialty board examination, a study platform has been developed with aims at improving their performance, resulting in better, top of the rank marks when compared to all national residency programs.

In short, a Department well settled on the present but firmly advancing to the future. 